Research Article

\title{
Interval Pricing Study of Deposit Insurance in China
}

\author{
Sulin Wu, Shenggang Yang, Yifan Wu, and Sangzhi Zhu $\mathbb{D}$ \\ College of Finance and Statistics, Hunan University, Changsha 410006, China \\ Correspondence should be addressed to Sangzhi Zhu; zhusangzhi@hnu.edu.cn
}

Received 22 May 2020; Revised 21 September 2020; Accepted 13 October 2020; Published 26 October 2020

Academic Editor: Francisco R. Villatoro

Copyright (c) 2020 Sulin Wu et al. This is an open access article distributed under the Creative Commons Attribution License, which permits unrestricted use, distribution, and reproduction in any medium, provided the original work is properly cited.

\begin{abstract}
This paper first proposes a European option pricing method for deposit insurance based on triangular intuitionistic fuzzy numbers. In the proposed method, we take into account the randomness and fuzziness of bank asset value simultaneously, and hence, the method can adequately reflect the high uncertainty of bank asset value. This method fuzzifies the value of bank asset, resubmits it into the original deposit insurance option pricing model as a fuzzy random variable, and then gives an analytic formula of deposit insurance rates using a risk-neutral method. After this, we have also conducted a numerical analysis. In specific, we have obtained the premium interval and presented the static analysis of key parameters. Finally, seven small- and middle-sized banks in Hunan Province in China are used as examples to validate the proposed interval pricing model. The Black-Scholes option pricing model and Yoshida's triangular fuzzy model are also employed for comparison. The research results show that the interval rates obtained from the proposed European option pricing method for deposit insurance can better reflect the uncertainty of bank asset evaluation than the fixed rates obtained from the Black-Scholes option pricing model. Moreover, the model proposed in this paper is also superior to Yoshida's model in practice.
\end{abstract}

\section{Introduction}

In May 2015, the Deposit Insurance Regulations came into effect in China, which marked the start of the official establishment of China's deposit insurance system. The deposit insurance system, the macroprudential supervisory authority, and the final lender function of the central bank constitute the national financial safety net together. As an explicit system, the deposit insurance system not only effectively relieves the pressure of "the last guarantee" on the central bank of China but also reduces the moral hazard and adverse selection under the implicit deposit insurance system. It also increases the confidence of depositors in the banking system, effectively prevents the bank runs, and maintains the stability of the financial system. According to official statistics of the IADI (International Association of Deposit Insurers), as of July 2019, a total of 145 countries (regions) had established their own deposit insurance system. However, the acceptability of deposit insurance for banks depends to a large extent on the premium structure. Therefore, how to determine the deposit insurance rate is the core of the deposit insurance system [1].
A large amount of literature on deposit insurance pricing can be found. The most significant milestone is in 1977; Merton [1] found that there is an isomorphic relationship between deposit insurance and common stock put options, so he priced deposit insurance based on the European option pricing method developed by Black and Scholes [2] and Merton [3]. In the next several decades, deposit insurance pricing has been extensively studied on the basis of Merton. For the parameters that cannot be observed in the model, Marcus and Shaked [4] believe that the bank assets are random variables obeying the lognormal distribution. They estimated the bank asset value and asset volatility and obtained the deposit insurance value. Duan $[5,6]$ employed the maximum likelihood method to improve the model and derived an estimate of the bank's asset value. As to the issue that the original model in Merton [1] ignores the impact of regulatory policies, Merton [7] and Ronn and Verma [8] improved the model by taking the supervision cost and tolerant policy into consideration, respectively. Liu and Yang [9] used equity capital and subordinated debt as the regulatory capital of the bank and found that the more the regulatory capital, the lower the premium paid. Chinese 
scholars have extended the original pricing model from the perspectives of debt settlement structure, commercial bank capital allocation, and income tax effect to obtain more realistic results [9-12]. The impact of credit risk, interest rate risk, and systemic risk on the pricing of deposit insurance has also been investigated [13-16]. Some scholars believe that the volatility of bank assets is time-varying, fully considering the impact of the heterogeneity of bank assets on deposit insurance prices [17-20].

The premium calculated by the option pricing method mainly depends on the input parameter value. In the rapidly changing financial markets, these parameter values tend to be highly uncertain, especially the value of the bank's assets. It is not only affected by the bank's own management and risk levels but also related to the judgment of deposit insurance fund managers on macroeconomic conditions and external environmental uncertainty. These factors commonly do not have a definite probability distribution, so it is difficult for decision-makers to accurately estimate the expected value, which means that, no matter how accurate the mathematical model is used, it is difficult to get a convincing premium value.

In recent years, fuzzy mathematics has been extensively applied in the field of economics to solve the problem of highly uncertain economic variables in classical models. Dong [21] argues that ambiguity and randomness are different from each other. To be specific, the risk occurs when people do not know the true value of the random variable, but the fuzzy problem arises when the probability distribution of the random variable is uncertain. Some scholars have introduced the concept of fuzzy mathematics into the European option pricing model. Wu [22-24] holds that when investors face uncertain stock return distributions, they tend to choose the worst result. Therefore, when the variable distribution is uncertain, applying the fuzzy theory proposed by Zadeh [25] to the European option pricing model has great significance. Numerous studies take the randomness and ambiguity of variables into consideration in the construction of the European option pricing model and give reasonable option price ranges. The results show that the interval of European option prices can better describe the rapid changes in the financial market, which is helpful for making decisions by investors [26-28]. Some other scholars improve the conventional risk assessment based on the fuzzy theory. Zhao Yuan [29] established a risk fuzzy matrix and ranked the risks with the evaluation results of some scholars to provide a more practical and effective way for risk prevention and decision management. Arunraj [30] applied the fuzzy theory to estimate the risk value interval and pointed out that the risk assessment model with both randomness and ambiguity can describe more uncertainty. However, few researchers applied fuzzy theory to deposit insurance pricing, and therefore, there is still a theoretical gap in the current research.

Compared with the existing researches on deposit insurance pricing, the main contribution of this study is taking the ambiguity of the value of bank assets into account and expanding the deposit insurance pricing model with risk neutrality. Some scholars have studied the option pricing problem under stochastic volatility, and some studies have also considered the randomness and ambiguity and given the option price range. However, there are few studies on the interval pricing of deposit insurance. Thus, this paper applies the European option pricing method based on the triangular intuitionistic fuzzy number to the field of deposit insurance, which not only fills the theoretical gap of deposit insurance pricing but also gives the deposit insurance a more scientific economic meaning. In addition, this paper has carried out the numerical analysis and provided the interval rate of deposit insurance. The influence of the changing of different factors on the premium with the triangular intuitionistic fuzzy number has been also studied. Finally, the proposed deposit insurance pricing model is validated and compared with the Black-Scholes option pricing model and Yoshida's triangular fuzzy model with seven midsmall banks in Hunan Province, China. It should be noted that, similar to the Black-Scholes model, Yoshida's triangular fuzzy model is also an option pricing model. For the comparison purpose, this study also applies Yoshida's triangular fuzzy model for the interval pricing of deposit insurance.

The remaining part of this paper is organized as follows. Section 2 presents the research motivations. Section 3 provides the methodology and modeling. It is followed by the numerical analysis in Section 4. Section 5 is the model application and comparison. Section 6 gives the concluding statements.

\section{Research Motivations}

This study about the interval pricing problem of deposit insurance is mainly driven by the following three factors.

First of all, the estimated value of the parameters often deviates from the actual value, so the calculated premium value is not adequate to be applied in the rapidly changing economic environment. According to Merton's deposit insurance pricing model, certain deposit premium value can be calculated, which depends on the input parameter value, such as the asset value of the bank. However, the deposit insurance system is effective in advance. On the one hand, the regulatory authorities cannot accurately estimate the value of bank assets, deposit balances, and other parameters of banks in the rapidly changing financial market. These parameters often vary with the macroeconomic environment and the bank's operation and management. On the other hand, the uncertainty of the parameter probability distribution reduces the applicability of the model. Therefore, the high uncertainty of the parameter value greatly affects the credibility of the premium value, which means that no matter how accurate the mathematical model is used, the premium value will not be very convincing. In addition, changes in the level of economic and financial development, deposit structure, and the cumulative level of deposit insurance funds will also affect the decision-making of the regulatory authorities, further increasing the difficulty for them to accurately set insurance premium rates.

Secondly, in the practical sense, setting the premium rate as an interval is in line with China's overall development 
goals. In 2014, Premier of the State Council of China Li Keqiang mentioned in the government work report that "the economic operation is in a reasonable range," which has great effects on the transformation of China's economic development. The China Government Work Report 2016 clearly set the target range for economic growth to be $6.5 \%-$ $7 \%$. Afterward, the uncertainty of economic development in China has become increasingly prominent, and the pressures of economic transformation and structural adjustment have increased. In 2019, the government meeting once again decreased the economic growth target to $6 \%-6.5 \%$. As shown in Figure 1, the 13 provinces in the red zone set their economic growth targets as intervals in their government reports from 2017 to 2019. In particular, in 2019, 11 provinces adjusted their economic growth targets to intervals for the first time. A reasonable economic growth interval not only increases the flexibility of achieving economic goals but also takes into account multiple development goals such as stabilizing employment and preventing risks, thereby promoting the high-quality development of China's economy and increasing the resilience of economic development.

Finally, the COVID-19 epidemic has been a major blow to the world economy as the global economic uncertainty is worsening and the international situation is becoming more and more complex. According to the Economic Policy Uncertainty Index (EPU) proposed by Baker et al. [31], China's EPU has increased significantly since the beginning of 2018. As shown in Figure 2, in October 2019, the EPU index reached 970.83 , which is approximately 3.57 times the global EPU. Affected by the epidemic, China's EPU rose again to 934.72 in May 2020, and the global EPU reached 423.40, significantly higher than 196.14 during the financial crisis in 2008. With China playing an increasingly important role in the global economy, the responsibility of China to stabilize the smooth operation of the financial system is becoming heavier. Under the dual background of external epidemic impact and internal economic transformation, China has flexibly adopted a variety of monetary and fiscal policies to repair and stabilize the economy. As the direct object of macroeconomic policy and an important part of the financial market, the structure of assets and liabilities of commercial banks is also facing great uncertainty, and the liquidity risk cannot be ignored.

Therefore, in the environment with increasing external economic uncertainty, the deposit insurance system should play a better role in the financial safety net, safeguard the interests of depositors, stabilize public confidence, and guard against major risks caused by bank runs. When setting the premium, the regulatory authorities should not only fully consider the current economic level, deposit structure, and the accumulated level of premium fund but also make flexible adjustments according to the operation conditions and risk level of each commercial bank. If the regulatory authorities can replace the original fixed premium with a reasonable premium range, the deposit insurance system can not only fully protect the rights and interests of depositors but also enable the insured institutions to allocate funds efficiently and therefore maintain the effective and efficient operation of the financial system.

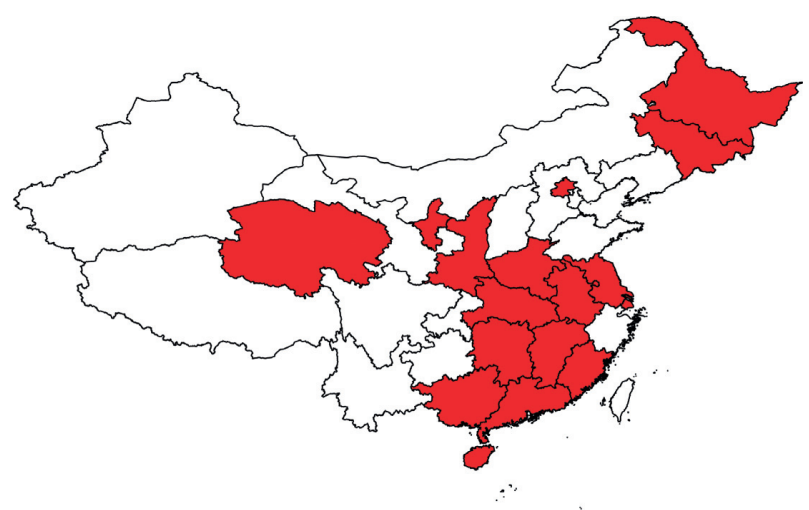

Figure 1: Provinces whose economic growth targets are set as intervals from 2017 to 2019.

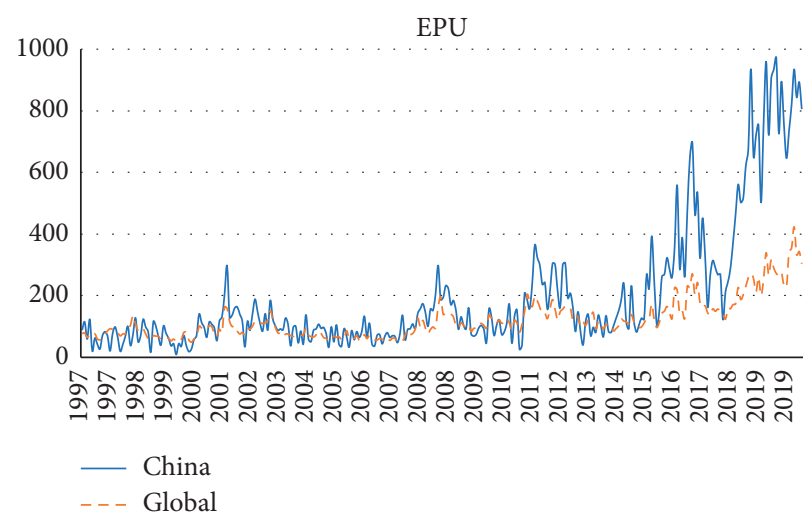

FIgure 2: China and the global economic policy uncertainty indicators.

\section{Methodology and Modeling}

3.1. A Model for Pricing Deposit Insurance. Merton [1] pioneered the application of the Black-Scholes option pricing formula in deposit insurance pricing [32]. He pointed out that deposit insurance is essentially a put option on the asset of the bank, which is purchased by a bank from a third-party guarantor. There is an isomorphic relationship between deposit insurance and common stock put options. The principal and interest of deposits that the bank had promised to pay at the maturity is corresponding to the exercise price, and the value of the bank's asset is corresponding to the common stock's price. In the deposit insurance system, if the value of a bank's assets is less than the total payment promised, the bank will execute the right to sell its asset at its "exercise price," which is at least equal to the promised payment, and the guarantor needs to carry out its obligation to pay the discrepant part between the value of the asset and the promised payment. In contrast, if the value of a bank's assets exceeds the promised payment, then depositors get the total payment without the guarantor. According to the 
Black-Scholes put option pricing formula, the deposit insurance premium can be written as

$$
\begin{aligned}
& G=B e^{-r(T-t)} N\left(-D_{1}\right)-\operatorname{VN}\left(D_{2}\right) \\
& D=B e^{-r(T-t)},
\end{aligned}
$$

where $\quad D_{1}=\left(\log (V / B)+(T-t)\left(r-(1 / 2) \sigma^{2}\right) / \sigma \sqrt{T-t}\right)$, $D_{2}=D_{1}+\sigma \sqrt{T-t}$, $\sigma$ is the standard deviation of logarithmic changes in the value of the assets over the period of deposit, $B$ is the promised payment on the maturity date of the deposits at time $T, D$ is the current value of insured deposits at time $t$, and $V$ is the current value of bank's asset at the time of $t$.

Let $g=(G / D), x=(V / D), \tau=\sigma^{2}(T-t)$. According to equations (1) and (2), $g$ can be written as a function of two variables:

$$
g(x, \tau)=N\left(-d_{1}\right)-x N\left(-d_{2}\right),
$$

where $\quad d_{1}=(\log (x)-(\tau / 2) / \sqrt{\tau}), d_{2}=(\log (x)+(\tau / 2) /$ $\sqrt{\tau}), g$ is the price of the guarantee per dollar of insured deposits, $x$ is the asset value-to-deposit ratio at the time of $t$, and $\tau$ is the variance of the logarithmic changes in the value of the assets over the period of deposit.

The deposit insurance pricing model proposed by Merton in 1978 has become the cornerstone of the deposit insurance pricing model based on the modern option pricing theory. However, due to the volatility of the financial market, the deposit insurance price under this model is not convincing even if an accurate analytical solution is used. There are three reasons that we use the price interval of deposit insurance in this paper instead of a specific price calculated in the model proposed by Merton. Firstly, some input parameters in the original pricing model cannot be accurately estimated, especially the value of bank assets. The guarantor has difficulties in evaluating the precise value of the bank's assets, then requiring the bank to pay corresponding insurance premium because the value of the bank's assets not only depends on its management and risk control capability but also associates with the macroeconomic environment. Secondly, the probability distributions of parameters in Merton's model are given or can be reasonably assumed, but many factors such as external accidence and the attitude of the guarantor in evaluating asset can also affect the assessment of assets' value, which are difficult to be measured by probability or stochasticity, so a specific value of assets may not include enough information. Finally, the managers or the guarantor of the deposit insurance should consider the current level of economic development, deposit structure of the banking industry, and the accumulated level of the deposit insurance fund. These factors also change from time to time. Hence, we capture the uncertainty of the value of the bank's assets with the triangular intuitionistic fuzzy number for a more reasonable price interval of deposit insurance.

3.2. Triangular Intuitionistic Fuzzy Number. The fuzzy number is used to represent uncertain and incomplete information from 1965 [25]. Before presenting the deposit insurance price with the triangular intuitionistic fuzzy number, we give the definition of the triangular intuitionistic fuzzy number.

Definition 1. Let $\tilde{a}=\left\langle\left(a_{1}, a, a_{2}\right) ; \omega_{\tilde{a}}, v_{a}\right\rangle$ be a triangular intuitionistic fuzzy set on the real number set $R$, and its degree of membership $\theta_{a}$ and degree of nonmembership $\eta_{a}$ are defined as

$$
\theta_{a}(x)= \begin{cases}\frac{x-a_{1}}{a-a_{1}} \omega_{a}, & a_{1} \leq x<a, \\ \omega_{a}, & x=a, \\ \frac{a_{2}-x}{a_{2}-a} \omega_{a}, & a<x \leq a_{2}, \\ 0, & x<a_{1}, x>a_{2},\end{cases}
$$

$$
\eta_{a}(x)= \begin{cases}\frac{a-x+u_{a}\left(x-a_{1}\right)}{a-a_{1}}, & a_{1} \leq x<a, \\ u_{a}, & x=a, \\ \frac{x-a+u_{a}\left(a_{2}-x\right)}{a_{2}-a}, & a<x \leq a_{2}, \\ 1, & x<a_{1}, x>a_{2},\end{cases}
$$

where $\omega_{a}$ is the maximum degree of membership; $u_{a}$ is the minimum degree of nonmembership; and the constraints are $0 \leq \omega_{a} \leq 1,0 \leq u_{a} \leq 1$, and $0 \leq \omega_{a}+u_{a} \leq 1$. Thus, we call $\tilde{a}=\left\langle\left(a_{1}, a, a_{2}\right) ; \omega_{\tilde{a}}, v_{a}\right\rangle$ as a triangular intuitionistic fuzzy number, where $a_{1}$ and $a_{2}$ are the lower and the upper bounds of the fuzzy number, respectively. $a$ is the value in the fuzzy set that receives the most possible value. The most pessimistic value of $\tilde{a}$ is $a_{1}$ and the most optimistic value of is $a_{2}$. Their degrees of membership and nonmembership are 0 and 1 , respectively.

Let $\pi_{a}^{\sim}(x) \triangleq 1-\theta_{a}(x)-\eta_{a}(x)$ and $\pi_{a}^{\sim}(x)$ be the intuitionistic fuzzy index of the triangular intuitionistic fuzzy number and present the hesitancy degree of $x$ subordinate to $\tilde{a}$. From the definition of triangular intuitionistic fuzzy number, $\theta_{\tilde{a}}$ and $\eta_{\tilde{a}}$ are the functions of variables $\omega_{\tilde{a}}$ and $u_{\tilde{a}}$ separately, so $\pi_{\tilde{a}}(x)$ is determined by $\omega_{\tilde{a}}$ and $u_{\tilde{a}}$ jointly.

Lemma 1. Particularly, when $\omega_{a}^{-}=1, u_{\tilde{a}}=0$, and then $\pi_{\tilde{a}}(x)=0$, the triangular intuitionistic fuzzy number is transformed into the triangular fuzzy number. Therefore, the triangular intuitionistic fuzzy number is a more general form of the triangular fuzzy number, while the triangular fuzzy number is a degenerate form of the triangular intuitionistic fuzzy number.

3.3. The Value of Bank's Assets under the Triangular Intuitionistic Fuzzy Number. As mentioned above, the value of a bank's assets cannot be measured by a certain probability because of the uncertainty of information, and thus the price of deposit insurance calculated by it is not convincing. So 
capturing the uncertainty of the value of the bank's assets plays a pivotal role in the deposit insurance pricing. Using the triangular intuitionistic fuzzy number that has given above, let $\widetilde{V}_{t}$ present the value of the bank's assets under the triangular intuitionistic fuzzy number; the specific definition of it can be written as equations (6) and (7).

Definition 2. The definitions of the cut set of $\widetilde{V}_{t}$ is ${ }^{\alpha} \widetilde{V}_{t}^{\beta} \triangleq\left\{x \mid \theta_{V} t(x) n \geq q \alpha h, \eta_{V} x(x) 7 \leq C \beta\right\}$. $\alpha$-cut set of $\widetilde{V}_{t}$ is defined as ${ }^{\alpha} \widetilde{V}_{t} \triangleq\left\{x \mid \theta_{V} t(x) n \geq q \alpha\right\}$, and $\beta$-cut set of $\widetilde{V}_{t}$ is defined as $\widetilde{V}_{t}^{\beta} \triangleq\left\{x \mid \eta_{V} t(x) n \leq q \beta\right\}$. $\alpha$ and $\beta$ satisfy the constraints of $0 \leq \alpha \leq \omega_{V}, u_{V} \leq \beta \leq 1$, respectively.

According to Yoshida's method of processing the stock price [26], we use a similar method to get the equation of the fuzzy value of the bank's assets. Let $V_{1} \triangleq V_{t}-a_{t}$, $V_{2} \triangleq V_{t}+a_{t}, a_{t}=c V_{t}$, where $c$ is a constant satisfying $0<c<1$. Then, we obtain the following expression of the $\alpha$-cut set and $\beta$-cut set of $\widetilde{V}_{t}$ :

$$
\begin{aligned}
& { }^{\alpha} \widetilde{V}_{t} \triangleq\left[{ }^{\alpha} I_{1}(V),{ }^{\alpha} I_{2}(V)\right]=\left[\frac{V_{1}+\alpha\left(V-V_{1}\right)}{\omega_{\tilde{V}}}, \frac{V_{2}-\alpha\left(V_{2}-V\right)}{\omega_{\widetilde{V}}}\right], \\
& \widetilde{V}_{t}^{\beta} \triangleq\left[I_{1}^{\beta}(V), I_{2}^{\beta}(V)\right]=\left[\frac{(1-\beta) V+\left(\beta-u_{\tilde{V}}\right) V_{1}}{1-u_{\tilde{V}}}, \frac{(1-\beta) V+\left(\beta-u_{\widetilde{V}}\right) V_{2}}{1-u_{\tilde{V}}}\right] .
\end{aligned}
$$

According to the cut set of $\widetilde{V}_{t}$ we have defined above, ${ }^{\alpha} \widetilde{V}_{t}^{\beta}$ can be presented as follows:

$$
\widetilde{V}_{t}^{\beta} \alpha \triangleq\left[\max \left(I_{1} \alpha, I_{1}^{\beta}\right), \min \left(I_{2} \alpha, I_{2}^{\beta}\right)\right]
$$

Theorem 1. The $(\alpha, \beta)$-cut set of fuzzy value of bank's assets defines an operator $\Delta=\alpha\left(1-u_{\widetilde{V}}\right)-(1-\beta) \omega_{\widetilde{V}}$, if $\Delta>0$, then ${ }^{\alpha} \widetilde{V}_{t}^{\beta}=\left[{ }^{\alpha} I_{1}(V),{ }^{\alpha} I_{2}(V)\right]$; if $\Delta \leq 0$, then ${ }^{\alpha} \widetilde{V}_{t}^{\beta}=\left[I_{1}^{\beta}(V), I_{2}^{\beta}(V)\right]$.

\subsection{The Triangular Intuitionistic Fuzzy Price of Deposit} Insurance. After getting the triangular intuitionistic fuzzy value of the bank's assets, we expect to get the triangular intuitionistic fuzzy price of the deposit insurance instead of an estimated value in the original deposit insurance pricing model. There are a number of factors having effects on the triangular intuitionistic fuzzy price of deposit insurance. Not only those factors considered in the model proposed by Merton, such as the triangular intuitionistic fuzzy value of the assets of the bank, the variance of the change in the assets' value, the maturity of the deposit, the total amount of principal, and interest and free-risk rate but also the fuzzy parameter $c$, cut set of the fuzzy value of assets, the maximum degree of membership $\omega_{\widetilde{V}}$, and the minimum degree of nonmembership $u_{\tilde{V}}$ are also included in our formula for the deposit insurance pricing. The formula in different situations can be written as equations (9) and (10).

If $\Delta>0$, we can get

$$
{ }^{a} G_{\tilde{V}, \pm}^{\beta}=\left[\left(1 \pm \frac{\omega_{\tilde{V}}-\alpha}{\omega_{\tilde{V}}} c\right) \cdot N\left(D_{2}^{ \pm}\right)-1\right] V+B e^{-r(T-t)} N\left(-D_{1}^{ \pm}\right),
$$

$$
{ }^{\alpha} G_{\tilde{V}, \pm}^{\beta}=\left[\left(1 \pm \frac{u_{\tilde{V}}-\beta}{1-u_{\tilde{V}}} c\right) \cdot N\left(D_{2}^{ \pm}\right)-1\right] V+B e^{-r(T-t)} N\left(-D_{1}^{ \pm}\right),
$$

where $D_{1}^{ \pm}=\left(\log \left(1 \pm\left(u_{\widetilde{V}}-\beta / 1-u_{\widetilde{V}}\right) c\right)+\log (V / B)+(T-\right.$ t) $\left.\left(r-(1 / 2) \sigma^{2}\right) / \sigma \sqrt{T-t}\right) D_{2}^{ \pm}=D_{1}^{ \pm}+\sigma \sqrt{T-t}$.

For conciseness, the deposit insurance interval can be presented as ${ }^{\alpha} G_{\tilde{V}_{+}}^{\beta}=\left[{ }^{\alpha} G_{\widetilde{V}_{-}}^{\beta},{ }^{\alpha} G_{\widetilde{V}_{+}}^{\beta}\right]$, following a similar symbol which cán also bé expréssed in the form of an interval.

In the reality, the guarantors of deposit insurance in China always make the price of the guarantee per Yuan of insured deposits instead of the total insurance payment of banks depending on the total deposit at the beginning of the period, so we further give the formula for the fuzzy price of unit insured deposit; let $g=(G / D), x=(V / D)$; then the formula can be written as equations (11) and (12).

If $\Delta>0$, then

$$
{ }^{a} g_{\tilde{x}, \pm}^{\beta}=\left[\left(1 \pm \frac{\omega_{\tilde{V}}-\alpha}{\omega_{\tilde{V}}} c\right) \cdot N\left(d_{2}^{ \pm}\right)-1\right] x+N\left(-d_{1}^{ \pm}\right),
$$

where $d_{1}^{ \pm}=\left(\log \left(1 \pm\left(\omega_{\widetilde{V}}-\alpha / \omega_{\widetilde{V}}\right) c\right)+\log x-(\tau / 2) / \sqrt{\tau}\right)$, $d_{2}^{ \pm}=d_{1}^{ \pm}+\sqrt{\tau}, \tau=\sigma^{2}(T-t)$.

If $\Delta \leq 0$, then

$$
{ }^{a} g_{\tilde{x}, \pm}^{\beta}=\left[\left(1 \pm \frac{u_{\tilde{V}}-\beta}{1-u_{\tilde{V}}} c\right) \cdot N\left(d_{2}^{ \pm}\right)-1\right] x+N\left(-d_{1}^{ \pm}\right),
$$

where $d_{1}^{ \pm}=\left(\log \left(1 \pm\left(u_{\widetilde{V}}-\beta / 1-u_{\widetilde{V}}\right) c\right)+\log x-(\tau / 2) / \sqrt{\tau}\right)$, $d_{2}^{ \pm}=d_{1}^{ \pm}+\sqrt{\tau}, \tau=\sigma^{2}(T-t)$.

where $D_{1}^{ \pm}=\left(\log \left(1 \pm\left(\omega_{\tilde{Y}}-\alpha / \omega_{\tilde{V}}\right) c\right)+\log (V / B)+(T-t)\right.$ $\left.(r-(1 / 2)) \sigma^{2} / \sigma \sqrt{T-t}\right), D_{2}^{\underline{Y}}=D_{1}^{ \pm}+\sigma \sqrt{T-t}$.

If $\Delta \leq 0$, we can get 


\section{Numerical Analysis}

After giving the expression of the price interval of unit deposit insurance, the numerical examples and analysis of parameter sensitivity are presented in this section. The parameters of the benchmark model are presented in Table 1.

4.1. Numerical Examples. Under the setting of the benchmark model, when $u_{\tilde{V}}=0.05$ and other parameters are set above, the interval of the triangular intuitionistic fuzzy price of unit deposit insurance is [0.064268, 0.123105]. If we let $u_{\tilde{V}}=0.02$ and keep other parameters unchanged, we obtain the interval $[0.063098,0.121742]$. If we let $u_{V}=0.01$, price interval contracts further to [0.062709, 0.121283]. We take these examples to illustrate that with the decrease of $u_{\tilde{V}}$ the hesitancy degree increases. With the manager or the guarantor of deposit insurance becoming more cautious in assessing banks' performance and risk level, the price interval of unit deposit insurance contracts.

4.2. Parameter Analysis. Figure 3 demonstrates the relationship between the fuzzy factor and the price interval of deposit insurance. $g_{1}$ represents the lower bound and $g_{2}$ represents the upper bound of the price interval of unit deposit insurance $\left[g_{1}, g_{2}\right]$. The upper bound increases, while the lower bound decreases with the increase of $c$. According to our definition, $c$ represents the extent of changes in the bank's assets, which is taken into account in evaluating the bank's assets. As $c$ increases, the interval of the value of assets becomes wider, which means that the ability of the bank to burden the cost of deposit insurance is relatively higher, and then the guarantor can make the wider price interval of deposit insurance for it.

Figure 4 presents the relationship between $\beta$-cut and the price interval of deposit insurance. The upper bound increases, while the lower bound decreases with the increase of $\beta$-cut. When $\beta$-cut is larger than one specific value $(0.23$ approximately), both the lower and upper bounds remain unchanged, which means that the change of price interval of deposit insurance has a constraint of the cut set.

Figure 5 shows the relationship between asset to deposit $(x)$ and the price interval of deposit insurance. The effect of $x$ on the price interval is different as $x$ increases. When $x$ is smaller than 1, both the lower and upper bounds decrease obviously with the increase of $x$ and the magnitude of the interval is rather small. When $x$ is larger than 1 , the decrease of the upper bound is less than the decrease of the lower bound, and when $x$ increases over about 1.3, the upper bound slightly increases, while the lower bound still decreases. It is worth noting that when $x$ increases to 3 , the upper bound is about 0.14 , basically consistent with its counterpart when $x$ equals 1 . The result is in line with the actual situation. The guarantor makes a high price and smaller interval of deposit insurance when the bank absorbs too large amounts of deposits $(x=0.5)$ because the bank with such a capital structure is more likely to have liquidity risk and bank run. However, with the increase of the value of
TABle 1: Parameters of the benchmark model.

\begin{tabular}{lc}
\hline Parameter & Value \\
\hline Maturity & $T-t=1$ \\
Asset to deposit ratio & $x=1$ \\
Volatility & $\sigma=0.25$ \\
Fuzzy factor & $c=0.3$ \\
$\alpha$-cut & $\alpha=0.75$ \\
$\beta$-cut & $\beta=0.2$ \\
Membership degree & $\omega_{\tilde{V}}=0.95$ \\
Nonmembership degree & $u_{\tilde{V}}=0.05$ \\
\hline
\end{tabular}

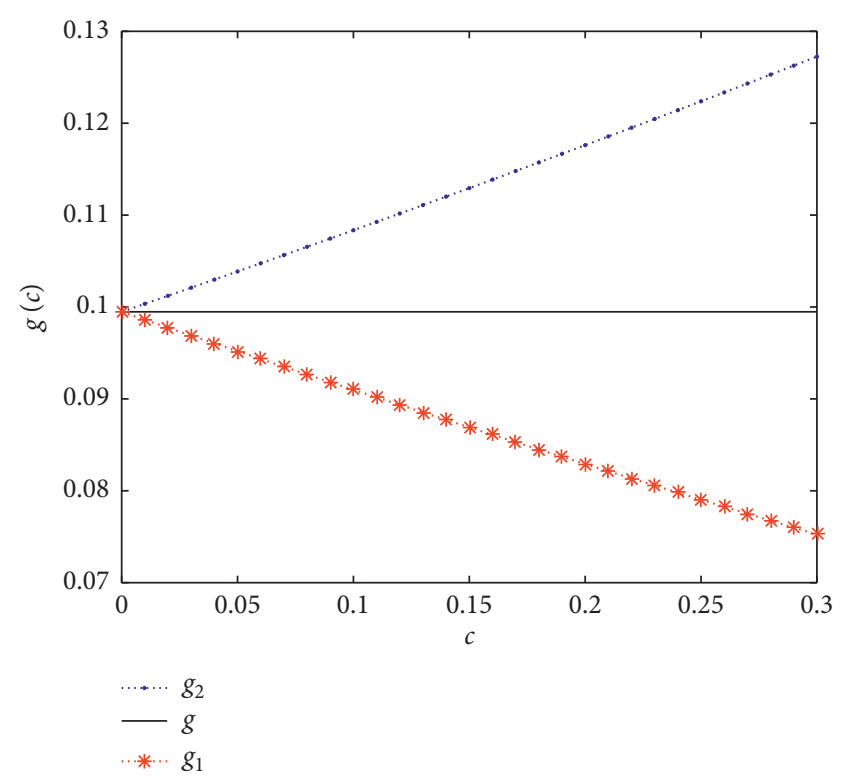

FIgURE 3: The relationship between the fuzzy factor and the price interval of deposit insurance.

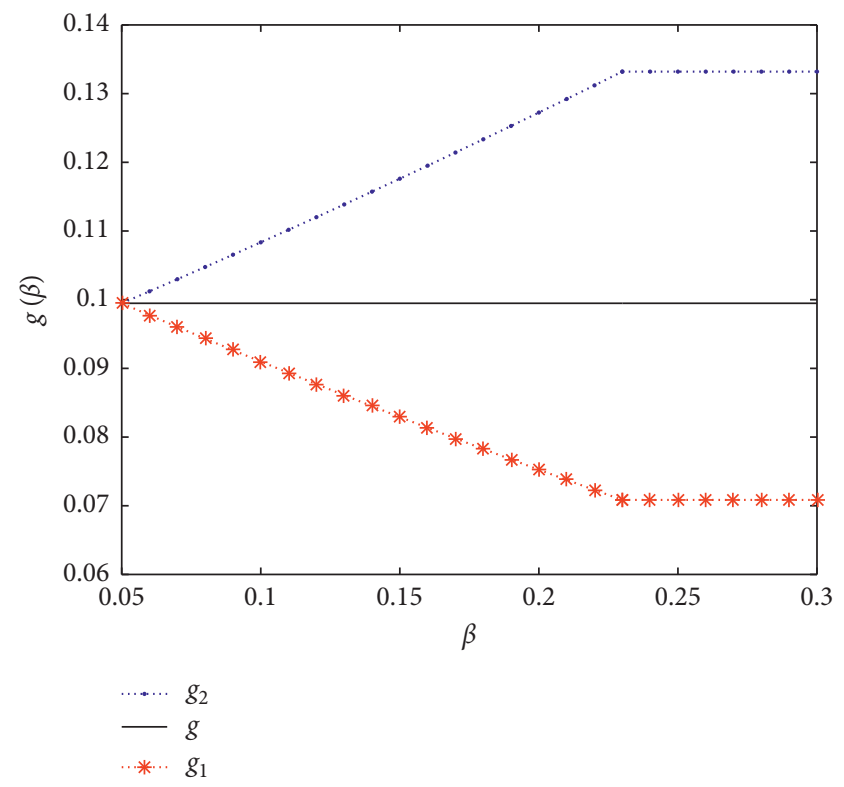

FIgURE 4: The relationship between $\beta$-cut and the price interval of deposit insurance. 


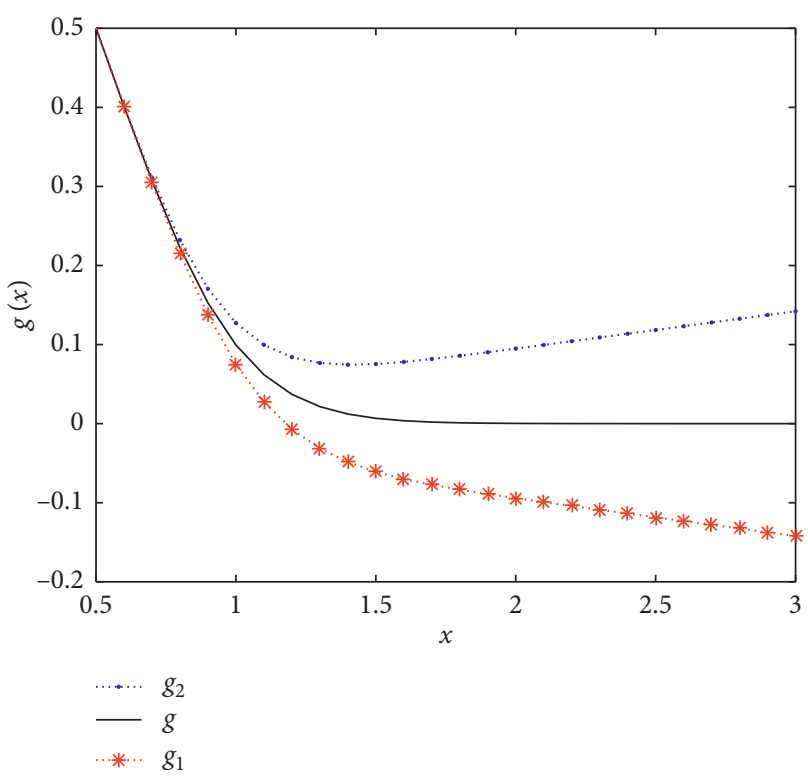

Figure 5: The relationship between $x$ and the price interval of deposit insurance.

assets, the bank can cope with the potential risk with adequate assets. Therefore, the guarantor properly lowers the deposit insurance price and provides a more flexible price interval for the bank.

Figure 6 shows how the volatility of assets' value affects the fuzzy price. It can be seen that the price of deposit insurance and volatility has a positive correlation. In other words, when the volatility of the value of assets increases, the bank is more likely to suffer from a decline in the value of assets, which would result in a rise of the probability of bankrupt, and therefore, the guarantor always requires the riskier bank to have a higher deposit insurance price to protect the depositors in this bank. We can also find that the magnitude of the price interval does not show a distinct change with the increase of $\sigma$.

\section{Model Application and Comparison}

To validate the applicability of the proposed European option pricing method for deposit insurance based on triangular intuitionistic fuzzy numbers to the banks in China from a practical perspective, this paper selects the semiannual data of seven small- and medium-sized banks in Hunan Province from June 2015 to the end of 2018. The asset volatility and the ratio of savings to assets of each bank are obtained by calculation. Considering the statistical frequency of premium data and the stability of bank management, in this part, we adjust the maturity and fuzzy factor. The specific parameter settings are shown in Table 2.

Apart from the proposed model in this paper, the BlackScholes option pricing model and Yoshida's triangular fuzzy model are also employed for comparison. After substituting the data of the seven commercial banks into the models, we obtained the premium payable per unit deposit of the seven banks with the change of deposit asset ratio. The results are

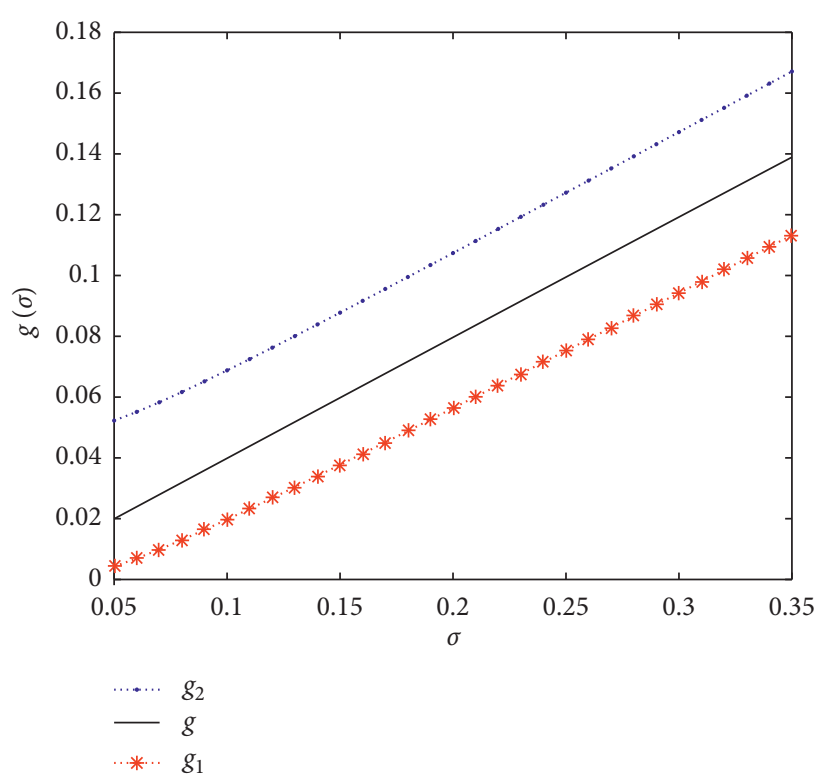

FIgURE 6: The relationship between $\sigma$ and the price interval of deposit insurance.

TAble 2: Parameters of the proposed model.

\begin{tabular}{lc}
\hline Parameter & Value \\
\hline$\alpha$-cut & $\alpha=0.75$ \\
$\beta$-cut & $\beta=0.2$ \\
Membership degree & $\omega_{\tilde{V}}=0.95$ \\
Nonmembership degree & $u_{\tilde{V}}=0.04$ \\
Maturity & $T-t=0.5$ \\
Risk-free rate & $r=0.05$ \\
Fuzzy factor & $c=0.01$ \\
\hline
\end{tabular}

shown in Table 3, where $g$ is the premium value obtained from the Black-Scholes model; $g_{1}$ and $g_{2}$ represent the lower and upper bounds of the premium rate of the triangular intuitionistic fuzzy model; $g_{11}$ and $g_{22}$ are the lower and upper bounds of premium rate of Yoshida's triangular fuzzy model.

We can see from Table 3 that the premium rates obtained by the Black-Scholes option pricing model are fixed values, while their counterparts by the triangular intuitionistic fuzzy model and Yoshida's triangular fuzzy model are intervals. From the year of 2015, China starts to develop the deposit insurance system, and it is still in its infancy. To make the deposit insurance system plays its role of enhancing the confidence of depositors and maintaining the stability of the financial system better, the regulatory authority should not only consider China's macroeconomic development, external environmental uncertainty, the country's overall deposit structure, and the accumulation of deposit insurance funds but also pay close attention to the management and risk levels of the insurance institutions. Hence, theoretically, the interval rate obtained by comprehensively considering various factors is more suitable for China's current deposit insurance system. 
TABle 3: Obtained premiums of the seven banks.

\begin{tabular}{|c|c|c|c|c|c|c|c|}
\hline \multirow[t]{2}{*}{ Bank code } & \multirow[t]{2}{*}{$x$} & \multirow[t]{2}{*}{ Sigma (\%) } & \multirow{2}{*}{$\begin{array}{c}\text { BS option pricing model } \\
\qquad g\end{array}$} & \multicolumn{2}{|c|}{$\begin{array}{l}\text { Triangular intuitionistic } \\
\text { fuzzy model }\end{array}$} & \multicolumn{2}{|c|}{$\begin{array}{l}\text { Yoshida's triangular } \\
\text { fuzzy model }\end{array}$} \\
\hline & & & & $g_{1}$ & $g_{2}$ & $g_{11}$ & $g_{22}$ \\
\hline 100051 & 1.1273 & 13.84 & 0.005537 & 0.003852 & 0.007229 & 0.003012 & 0.008076 \\
\hline 100053 & 1.1937 & 16.74 & 0.003819 & 0.001951 & 0.005691 & 0.001018 & 0.006628 \\
\hline 100068 & 1.1330 & 13.82 & 0.004963 & 0.003252 & 0.006680 & 0.002398 & 0.00754 \\
\hline 100069 & 1.1185 & 13.31 & 0.005702 & 0.004043 & 0.007368 & 0.003215 & 0.008203 \\
\hline 100092 & 1.1363 & 13.73 & 0.004544 & 0.002816 & 0.006277 & 0.001954 & 0.007146 \\
\hline 100098 & 1.1712 & 15.25 & 0.003697 & 0.000961 & 0.005525 & 0.001873 & 0.006441 \\
\hline 100107 & 1.1056 & 10.20 & 0.002826 & 0.001128 & 0.004531 & 0.000281 & 0.005385 \\
\hline
\end{tabular}

We can also see from Table 3 that the premium payable per unit deposit of the seven banks obtained from the BlackScholes option pricing model basically falls in both the premium rate intervals of the triangular intuitionistic fuzzy model and Yoshida's triangular fuzzy model. However, the rate range of triangular fuzzy is wider than that of the triangular intuitionistic fuzzy model. It is because the proposed triangular intuitionistic fuzzy model takes into account the hesitation of investors and thus is more generally applicable than Yoshida's model. In other words, Yoshida's model is a special case of the proposed model in this paper. Hence, the triangular intuitionistic fuzzy model proposed in this paper can play a better guidance role than Yoshida's model in practice.

\section{Conclusions}

In this study, the concept of triangular intuitionistic fuzzy numbers is applied to the European option pricing formula, and the interval pricing problem of deposit insurance is studied. Since the value of a bank's assets is closely linked to its management and risk levels, it is impossible to determine the accurate probability distribution of asset values in a rapidly changing financial market. Therefore, dealing with the value of bank assets with fuzzy measures is a way worth exploring. In addition, decision-makers need to fully consider the economic and financial development level, the structure of deposits, and the cumulative level of deposit insurance funds when determining the rate. From this perspective, the interval premium is a better reference for decision-makers than an accurate rate. This paper gives the analytic formula of interval premium after fuzzifying the value of assets and thus fills the gap in the theory of deposit insurance pricing. The rate interval is given by numerical examples, and the key parameters are statically analyzed. Finally, the proposed interval pricing model is validated and compared with the other two models. We can conclude that setting the deposit insurance interval is more applicable than the fixed rates for China's actual situation and the proposed deposit insurance interval pricing model is superior to Yoshida's model in practice.

\section{Appendix}

Merton believes that deposit insurance premiums can be calculated by the following formula:

$$
G=B e^{-r(T-t)} N\left(-D_{1}\right)-\mathrm{VN}\left(D_{2}\right)
$$

Because

$$
\begin{aligned}
& { }^{\alpha} \widetilde{V}_{t} \triangleq\left[{ }^{\alpha} I_{1}(V),{ }^{\alpha} I_{2}(V)\right]=\left[V_{1}+\frac{\alpha\left(V-V_{1}\right)}{\omega_{\tilde{V}}}, V_{2}-\frac{\alpha\left(V_{2}-V\right)}{\omega_{\tilde{V}}}\right], \\
& \widetilde{V}_{t}^{\beta} \triangleq\left[I_{1}^{\beta}(V), I_{2}^{\beta}(V)\right]=\left[\frac{(1-\beta) V+\left(\beta-u_{\tilde{V}}\right) V_{1}}{1-u_{\tilde{V}}}, \frac{(1-\beta) V+\left(\beta-u_{\tilde{V}}\right) V_{2}}{1-u_{\tilde{V}}}\right],
\end{aligned}
$$

$\Delta=\alpha\left(1-u_{\tilde{V}}\right)-(1-\beta) \omega_{\tilde{V}} ;$ when $\Delta>0, \quad{ }^{\alpha} \widetilde{V}_{t}^{\beta}=\left[{ }^{\alpha} I_{1}(V)\right.$, $\left.{ }^{\alpha} I_{2}(V)\right]$; when $\Delta \leq 0,{ }^{\alpha} \widetilde{V}_{t}^{\beta}=\left[I_{1}^{\beta}(V), I_{2}^{\beta}(V)\right]$.

We can get the following:When $\Delta>0$,

$$
{ }^{\alpha} \widetilde{V}_{t}^{\beta}=\left[\left(1-\frac{\omega_{\tilde{V}}-\alpha}{\omega_{\tilde{V}}} c\right) V_{t},\left(1+\frac{\omega_{\tilde{V}}-\alpha}{\omega_{\tilde{V}}} c\right) V_{t}\right],
$$

and when $\Delta \leq 0$,

$$
{ }^{\alpha} \widetilde{V}_{t}^{\beta}=\left[\left(1+\frac{u_{\tilde{V}}-\beta}{1-u_{\tilde{V}}} c\right) V_{t},\left(1-\frac{u_{\tilde{V}}-\beta}{1-u_{\tilde{V}}} c\right) V_{t}\right],
$$

where $0 \leq \alpha \leq \omega_{\widetilde{V}}, u_{\widetilde{V}} \leq \beta \leq 1$, and $V_{t}$ represents the most likely value of bank assets at time $t$.

Substituting the results of equations (A.4) and (A.5) into (A.1), we have the following:When $\Delta>0$, 


$$
{ }^{\alpha} G_{\widetilde{V}, \pm}^{\beta}=\left[\left(1 \pm \frac{\omega_{\tilde{V}}-\alpha}{\omega_{\tilde{V}}} c\right) \cdot N\left(D_{2}^{ \pm}\right)-1\right] V+B e^{-r(T-t)} N\left(-D_{1}^{ \pm}\right),
$$

where $D_{1}^{ \pm}=\left(\log \left(1 \pm\left(\omega_{\tilde{V}}-\alpha / \omega_{\tilde{V}}\right) c\right)+\log (V / B)+(T-t)\right.$ $\left.\left(r-(1 / 2) \sigma^{2}\right) / \sigma \sqrt{T-t}\right)$ and $D_{2}^{ \pm}=D_{1}^{ \pm}+\sigma \sqrt{T-t}$; when $\Delta \leq 0$,

$$
{ }^{\alpha} G_{\widetilde{V}, \pm}^{\beta}=\left[\left(1 \pm \frac{u_{\widetilde{V}}-\beta}{1-u_{\tilde{V}}} c\right) \cdot N\left(D_{2}^{ \pm}\right)-1\right] V+B e^{-r(T-t)} N\left(-D_{1}^{ \pm}\right),
$$

where $D_{1}^{ \pm}=\left(\log \left(1 \pm\left(u_{\widetilde{V}}-\beta / 1-u_{\widetilde{V}}\right) c\right)+\log (V / B)+(T-\right.$ t) $\left.\left(r-(1 / 2) \sigma^{2}\right) / \sigma \sqrt{T-t}\right)$ and $D_{2}^{ \pm}=D_{1}^{ \pm}+\sigma \sqrt{T-t}$.

Dividing the left and right sides of equations (A.6) and (A.7) by $D$, when $\Delta>0$,

$$
{ }^{\alpha} g_{\tilde{x}, \pm}^{\beta}=\left[\left(1 \pm \frac{\omega_{\widetilde{V}}-\alpha}{\omega_{\tilde{V}}} c\right) \cdot N\left(d_{2}^{ \pm}\right)-1\right] x+N\left(-d_{1}^{ \pm}\right),
$$

where $\quad d_{1}^{ \pm}=\left(\log \left(1 \pm\left(\omega_{\tilde{V}}-\alpha / \omega_{\tilde{V}} \quad\right) c\right)+\log x-(\tau / 2) /\right.$ $\sqrt{\tau}), d_{2}^{ \pm}=d_{1}^{ \pm}+\sqrt{\tau}, \tau=\sigma^{2}(T-t)$, and when $\Delta \leq 0$,

$$
\alpha g_{\tilde{x}, \pm}^{\beta}=\left[\left(1 \pm \frac{u_{\tilde{V}}-\beta}{1-u_{\tilde{V}}} c\right) \cdot N\left(d_{2}^{ \pm}\right)-1\right] x+N\left(-d_{1}^{ \pm}\right) \text {, }
$$

where $\quad d_{1}^{ \pm}=\left(\log \left(1 \pm\left(u_{\tilde{V}}-\beta / 1-u_{\widetilde{V}}\right) c\right)+\log x-(\tau / 2) /\right.$ $\sqrt{\tau}), d_{2}^{ \pm}=d_{1}^{ \pm}+\sqrt{\tau}, \tau=\sigma^{2}(T-t)$.

\section{Data Availability}

Data sharing not applicable to this paper as the data used to support the findings of this study belong to third parties and are authorized to authors for the research purpose only. The authors should anonymize data to protect privacy.

\section{Conflicts of Interest}

The authors declare that there are no conflicts of interests regarding the publication of this paper.

\section{Acknowledgments}

The financial support for this research was provided jointly by the National Natural Science Foundation of China (Grant nos. 71790593; 71850006; and 71903051) and the China Postdoctoral Science Foundation (Grant no. 2018M642965).

\section{References}

[1] R. C. Merton, "An analytic derivation of the cost of deposit insurance and loan guarantees," Journal of Banking and Finance, vol. 1, no. 1, pp. 3-11, 1977.

[2] F. Black and M. Scholes, "The pricing of options and corporate liabilities," Journal of Political Economy, vol. 81, no. 3, pp. 637-654, 1973.
[3] R. C. Merton, "Theory of rational option pricing," The Bell Journal of Economics and Management Science, vol. 4, no. 1, pp. 141-183, 1973.

[4] J. M. Alan and I. Shaked, "The valuation of FDIC deposit insurance using option-pricing estimates," Journal of Money, Credit and Banking, vol. 16, no. 4, pp. 446-460, 1984.

[5] J.-C. Duan, "Maximum likelihood estimation using price data of the derivative contract," Mathematical Finance, vol. 4, no. 2, pp. 155-167, 1994.

[6] J. C. Duan, "Correction: maximum likelihood estimation using price data of the derivative contract (mathematical finance 1994, 4/2, 155-167)," Mathematical Finance, vol. 10, no. 4 , pp. $461-462,2000$.

[7] R. C. Merton, "On the cost of deposit insurance when there are surveillance costs," Journal of Business, vol. 51, no. 7, pp. 439-451, 1978.

[8] E. Ronn and A. Verma, "Pricing risk-adjusted deposit insurance: an option-based model," Journal of Finance, vol. 41, no. 9, pp. 871-895, 1986.

[9] H. Liu and J. Yang, "Deposit insurance pricing based on bank supervision capital," Journal of Management Science and Engineering, vol. 14, no. 3, pp. 73-82, 2011.

[10] J. Zhang and R. Ren, "Deposits insurance pricing based on bank's capital allocation," Journal of Financial Research, vol. 1, no. 1, pp. 53-60, 2007.

[11] J. Zhang and R. Ren, "Debt structured deposit insurance pricing based on bank debt," Journal of Financial Research, vol. 6, no. 6, pp. 35-43, 2007.

[12] X. Jiang, J. Sun, and Y. Song, "Merton model deposit insurance pricing with income tax," Journal of Statistics and Information Forum, vol. 28, no. 3, pp. 22-27, 2013.

[13] J.-C. Duan, A. F. Moreau, and C. W. Sealey, "Deposit insurance and bank interest rate risk: pricing and regulatory implications," Journal of Banking \& Finance, vol. 19, no. 6, pp. 1091-1108, 1995.

[14] J. So and J. Z. Wei, "Deposit insurance and forbearance under moral hazard," Journal of Risk and Insurance, vol. 71, no. 4, pp. 707-735, 2004.

[15] J. Dermine and F. Lajeri, "Credit risk and the deposit insurance premium: a note," Journal of Economics and Business, vol. 53, no. 5, pp. 497-508, 2001.

[16] S.-C. Lee, C.-T. Lin, and M.-S. Tsai, "The pricing of deposit insurance in the presence of systematic risk," Journal of Banking \& Finance, vol. 51, pp. 1-11, 2015.

[17] J.-C. Duan and M.-T. Yu, "Capital standard, forbearance and deposit insurance pricing under GARCH," Journal of Banking \& Finance, vol. 23, no. 11, pp. 1691-1706, 1999.

[18] H. Liu, R. Li, and J. Yuan, "Deposit insurance pricing under GARCH," Finance Research Letters, vol. 26, pp. 242-249, 2018.

[19] Y Guo and J. Zhao, "Deposit insurance system, bank heterogeneity and individual bank risk," Economic Research Journal, vol. 52, no. 12, pp. 134-148, 2017.

[20] J. Yuan, H. Liu, and X. Liu, "Deposit insurance pricing based on time-varying volatility," Journal of Management Science and Engineering, vol. 22, no. 3, pp. 113-126, 2019.

[21] Z. Dong and X. Han, "Fuzzy disgust and herding behavior," Economic Science, vol. 2, pp. 51-64, 2008.

[22] H.-C. Wu, "Pricing European options based on the fuzzy pattern of Black-Scholes formula," Computers \& Operations Research, vol. 31, no. 7, pp. 1069-1081, 2004.

[23] H.-C. Wu, "European option pricing under fuzzy environments," International Journal of Intelligent Systems, vol. 20, no. 1, pp. 89-102, 2005. 
[24] H.-C. Wu, "Using fuzzy sets theory and Black-Scholes formula to generate pricing boundaries of European options," Applied Mathematics and Computation, vol. 185, no. 1, pp. 136-146, 2007.

[25] L. A. Zadeh, "Fuzzy sets," Information and Control, vol. 8, no. 3, pp. 338-353, 1965.

[26] Y. Yoshida, "The valuation of European options in uncertain environment," European Journal of Operational Research, vol. 145, no. 1, pp. 221-229, 2003.

[27] M. Zhang, X. Qin, and J. Nan, "European option binary tree pricing model based on triangular intuitionistic fuzzy numbers," System Engineering-Theory and Practice, vol. 33, no. 1, pp. 34-40, 2013.

[28] L. Ming and S. Yang, "European option pricing model based on investment hesitation," System Engineering-Theory and Practice, vol. 36, no. 6, pp. 1392-1398, 2016.

[29] Y. Zhao, J. Jiao, and Y. Zhao, "Risk evaluation method based on fuzzy theory," Journal of Systems Engineering and Electronics, vol. 37, no. 8, pp. 1825-1837, 2015.

[30] N. S. Arunraj, S. Mandal, and J. Maiti, "Modeling uncertainty in risk assessment: an integrated approach with fuzzy set theory and Monte Carlo simulation," Accident Analysis \& Prevention, vol. 55, pp. 242-255, 2013.

[31] S. R. Baker, N. Bloom, and S. J. Davis, "Measuring economic policy uncertainty*," The Quarterly Journal of Economics, vol. 131, no. 4, pp. 1593-1636, 2016.

[32] Y. Zhang, "Research on the model of deposit insurance pricing," Studies of International Finance, vol. 11, pp. 35-38, 2003. 